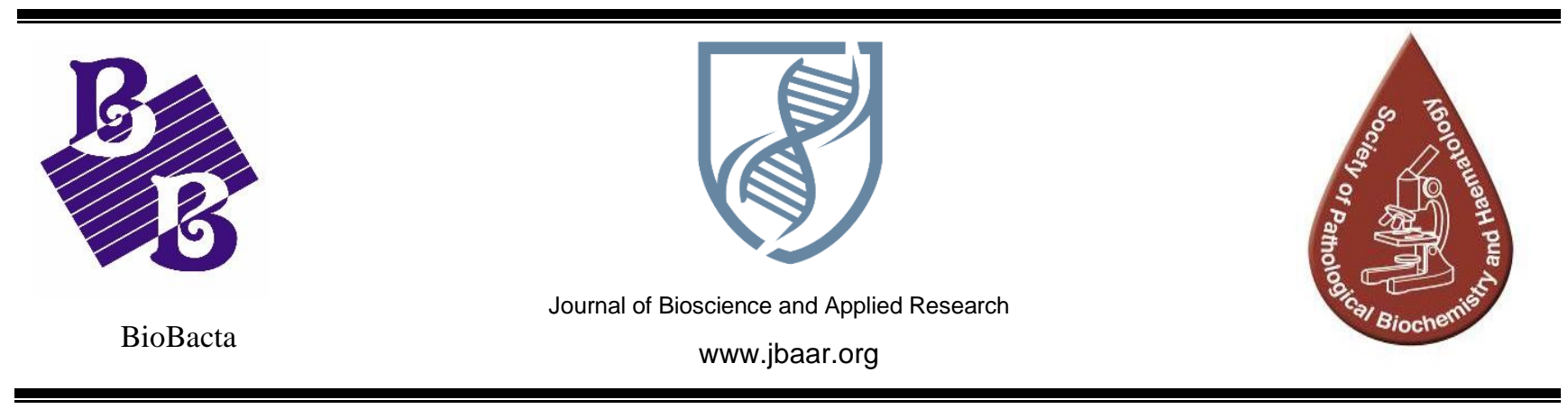

\title{
Protective role of rosemary extract against Etoposide induced liver toxicity, injury and KI67 alterations in rats
}

\author{
*Ehab Tousson, Ahmed Masoud, Ezar Hafez, Majd Almakhatreh \\ Department of Zoology, Faculty of Science, Tanta University, Tanta, Egypt \\ *Corresponding author: toussonehab@yahoo.com
}

\begin{abstract}
Etoposide is chemotherapeutic drugs that inhibit topoisomerase II activity and long been used for the treatment of human malignancies. The present study was designed to investigate the possible protective effect of rosemary extract against Etoposide-induced liver toxicity, injury, and KI67 alterations in rats. A total of 40 male Wister albino rats were divided randomly into four groups ( $1^{\text {st }}$ group was control; $2^{\text {nd }}$ group was treated with rosemary, $3^{\text {rd }}$ group was received Etoposide, and $4^{\text {th }}$ group was treated with both rosemary and Etoposide. The administration of Etoposide significantly caused elevation in ALT, AST, ALP, and liver damage while albumin, total proteins, and KI67 expressions were significantly decreased when compared with the control group. Co-treated rats with rosemary and Etoposide maintained the levels of the measured parameters. Finally, it could be concluded that rosemary has a promising role and it worth to be considered as a natural substance for protecting the liver toxicity and injury induced by Etoposide chemotherapy.
\end{abstract}

Keywords: Etoposide; Rosemary; Liver functions, KI67 immunohistochemistry; rat.

\section{Introduction}

Chemotherapy drugs cannot distinguish between the cancerous cells and the normal cells, which leads to the side effects (Tousson et al., 2014a-d, 2016, 2018a; Basuony et al., 2015; Bayomy et al., 2017; AlRasheed et al., 2017, 2018).

Etoposide is chemotherapeutic drugs that inhibit topoisomerase II activity and long been used for the treatment of human malignancies, where it is a semisynthetic compound derived from the plant podophyllum pelltatum (Bayomy et al., 2017; Shin et al., 2016; Tousson et al., 2018a). Etoposide is commonly used alone or in combination with other anticancer agents in the treatment of lung or stomach cancer, Hodgkin's lymphoma, and AID's.

Many plant extracts and their products have been shown to have significant antioxidant activity which may be an important property of medicinal plants associated with the treatment of several ill-fated diseases including liver toxicity (Saggu et al., 2014; Elmasry et al., 2017, 2018; Abd Eldaim et al., 2018; Akela et al., 2018; Oyouni et al., 2018; Tousson et al., 2018b).

Rosemary (Rosemarinus officinalis) is one of the household herbs that contains a number of phytochemicals, including rosmarinic acid, camphor, caffeic acid, ursolic acid, betulinic acid, and the antioxidants carnosic acid (Akela et al., 2018). Star anise fruits are traditionally used in Chinese medicine to treat stomach aches, vomiting, insomnia, dermal inflammation, and rheumatic pain as well as a common spice usage (El-Atrash et al., 2017). Extracts of rosemary leaves possess a variety of bioactivities in vitro including antioxidant, antibacterial, anti-tumor, antinociceptive, antiulcerogenic, antidiuretic, antidiabetic, antiinflammatory and antithrombotic agents 
(Habtemariam, 2016). Therefore; the present study was conducted to examine the possible modifying effects of rosemary aqueous extract against liver toxicity, liver injury, and Ki67 alterations induced by Etoposide in male rats.

\section{Materials and methods}

\subsection{Animals}

The experiments were performed on 40 male rats weighing $130 \pm 10 \mathrm{~g}$ and 10 week's age. The rats were kept in our Faculty animal house for one week before the experimental work and maintained on a standard rodent diet and water available ad libitum. After one week of acclimation, rats were equally divided into four groups.

\subsection{Experimental groups}

The $1^{\text {st }}$ group was the control group included rats received no treatment while the $2^{\text {nd }}$ group was star anise group included rats received star anise powdered suspension in distilled water (SA; 100 $\mathrm{mg} / \mathrm{kg} \mathrm{BW}$ ) daily by oral gavages for four weeks. The $3^{\text {rd }}$ group was the etoposide group included rats that injected interprotinally with Etoposide $(1 \mathrm{mg} / \mathrm{kg}$ B.W/2 day) orally for four weeks (Tousson et al., 2018a). The $4^{\text {th }}$ group was the group which treated with star anise plus Etoposide for four weeks.

\subsection{Determination of Serum Enzymes}

At the end of the experimental period, animals have fasted overnight and for clinical chemistry, blood samples were individually collected from the inferior vena cava of each rat in non-heparinized glass and allowed to stand for $30 \mathrm{~min}$ at room temperature to clot before being centrifuged at 3000 rpm for $15 \mathrm{~min}$.

Both alanine transaminase (ALT/GPT) and aspartate transaminase (AST/GOT) activities in serum were assayed by using a commercial kit that was supplied by Humann (Germany) according to the method of Schumann and Klauke (2013); alkaline phosphatase (ALP) activity in serum was assayed by using a commercial kit that was supplied by Humann (Germany) according to the method of Moss and Henderson (1999). Albumin concentration in serum was assayed by using commercial kit that was supplied by Diamond (Egypt) according to the method of Doumas et al. (1971).

\subsection{Histopathological evaluation}

Immediately after decapitation rats were dissected, liver from different groups was quickly removed, washed in 0.9 saline solutions, and fixed in $10 \%$ neutral buffered formalin. After fixation, specimens were dehydrated, cleared, and embedded in molten paraffin. Kidney sections of 7 microns thickness was cut, mounted on clean slides and stained with Ehrlich's haematoxylin and counterstained with eosin as a routine method after Bancroft and Stevens (1990).

\subsection{Immunohistochemical detection of KI67:}

The expression of Ki67 immunoreactivity (Ki67ir) in the liver was detected using the avidin Biotin Complex (ABC) method according to Tousson et al. (2015). The sections were incubated with antimouse Ki67 monoclonal antibody (dilution 1:50, DAKO Japan Co, Ltd, Tokyo, Japan) for 1-2 hours at room temperature.

\subsection{Statistical Analysis}

Data were expressed as mean values $\pm \mathrm{SE}$ and statistical analysis was performed using one way ANOVA to assess significant differences among treatment groups. The criterion for statistical significance was set at $p<0.01$ for the biochemical data. All statistical analyses were performed using SPSS statistical version 16 software package (SPSS ${ }^{\circledR}$ Inc., USA).

\section{Results}

\subsection{Serum markers of liver damage}

Data presented in Table (1) showed that; GPT, GOT and ALP activities were significantly increased in serum of rats treated with Etoposide as compared to the control group $(P<0.05)$. A significant increase with co-treatment rosemary with Etoposide as compared with Etoposide treated group (Table 1).

On the other hand; total protein and albumin levels were significantly decreased in the serum of the Etoposide treated group as compared to the control group $(P<0.05)$ while rats co-treatment rosemary with Etoposide showed a significant increase in total protein and albumin levels as compared to Etoposide treated groups.

\subsection{Liver histopathology}

Liver sections of control and rosemary groups exhibited the normal architecture of the hepatocytes with prominent round, vesicular basophilic nuclei, and eosinophilic cytoplasm, and few spaced hepatic sinusoids arranged in-between the hepatic cords (Figure 1A\&1B).

Liver sections of Etoposide group exhibited moderate atrophied vacuolar degeneration hepatocytes, some apoptotic cells with deeply eosinophilic cytoplasm and small deeply stained pyknotic or fragmented nuclei, marked cellular infiltrations and marked dilation or congestion in central and portal veins, vacuolated hepatocytes (Figure 1C) Liver sections in co-treated Etoposide 
with rosemary, group exhibited a mild degree of improvement in hepatocytes that exhibits moderate vacuolated hepatocytes with mild cellular infiltrations were observed, in addition to mild to moderate congestion in central and portal veins (Figure 1D).

\subsection{Ki67 expressions in the kidney:}

The detection and distribution in Ki67 immunoreactivity (Ki67-ir) in liver sections in the different groups under study were revealed in Figures $2 \mathrm{~A}-2 \mathrm{D}$.
The liver section in control and rosemary groups shows a strong positive reaction for Ki67-ir (grade 4) in hepatocyte nuclei (Figures 2A\&2B). In contrast mild to faint positive reactions were detected for Ki67-ir (grade 1) in the liver sections in the Etoposide rats group (Figure 2C).

On the other hand; Moderate positive reactions for Ki67-ir (grade 3) were observed in liver sections of co-treated Etoposide with rosemary (Figure 2D).

Table 1: Changes in liver function parameters in different groups.

\begin{tabular}{|c|c|c|c|c|}
\hline Parameters & Control & Rosemary & Etoposide & Rosemary+Etoposide \\
\hline GPT (U/l) & $24.9 \pm 0.87^{\mathrm{b}}$ & $22.85 \pm 1.55^{\mathrm{b}}$ & $51.3 \pm 2.06^{\mathrm{a}}$ & $44.4 \pm 1.96^{\mathrm{ab}}$ \\
\hline GOT (U/l) & $127 \pm 3.55^{\mathrm{b}}$ & $124 \pm 2.96^{\mathrm{b}}$ & $216 \pm 7.28^{\mathrm{a}}$ & $195 \pm 6.17^{\mathrm{a}}$ \\
\hline ALP (U/l) & $135 \pm 7.02^{\mathrm{b}}$ & $121 \pm 5.47^{\mathrm{b}}$ & $203 \pm 6.05^{\mathrm{a}}$ & $195 \pm 5.42^{\mathrm{a}}$ \\
\hline Albumin (g/dl) & $3.81 \pm 0.15^{\mathrm{b}}$ & $3.91 \pm 0.23^{\mathrm{b}}$ & $2.99 \pm 0.30^{\mathrm{a}}$ & $3.43 \pm 0.31^{\mathrm{ab}}$ \\
\hline Total protein $(\mathrm{g} / \mathrm{dl})$ & $7.45 \pm 0.60^{\mathrm{b}}$ & $7.52 \pm 0.33^{\mathrm{b}}$ & $4.65 \pm 0.21^{\mathrm{a}}$ & $4.85 \pm 0.33^{\mathrm{a}}$ \\
\hline
\end{tabular}

Data are expressed as mean \pm SE of 10 observations. Superscripts of different letters differ significantly $(p<0.01)$ from each other. ${ }^{\mathrm{b}}$ Significantly different from Etoposide group. ${ }^{\mathrm{a}}$ Significantly different from control group.

\section{Discussion}

Chemotherapy involves the use of chemical agents to stop the growth and eliminate cancer cells even at distant sites from the origin of the primary tumor (Basuony et al., 2015; Hafez et al., 2017). However, it does not distinguish between cancer and normal cells, and eliminates not only the fastgrowing cancer cells but also other fast-growing cells in the body, including, hair and blood cells. The current study aimed to study the possible modifying effects of rosemary extract against liver toxicity induced by Etoposide in male albino rats.

Chemotherapy-induced hepatotoxicity is a common cause of abnormal liver function tests in patients, this hepatotoxicity is usually begins with vague clinical symptoms such as fatigue, anorexia, nausea, dark urine, right upper quadrant discomfort, and jaundice.

In the current study; a significant increase in GPT, GOT, and ALP in the Etoposide group however, this elevation decreased in the treated group with rosemary. On the other hand; a significant decrease in albumin, and total protein in the Etoposide group however, this depletion decreased in the treated group with rosemary. Elevated levels of serum AST and ALT enzymes are indicative of cellular leakage and loss of functional integrity of cell membranes in the liver (El-Moghazy et al., 2014; Saggu et al., 2014).

This result is in harmony with Saleh et al. (2014) and Basuony et al. (2015) who reported that, Cisplatin increased during treatments. Also; this current result is in harmony with Tousson er al. (2014b, 2014c) who reported that; methotrexateinduced hepatic and renal toxicity in male rats and the increased in liver function associated with free radicals trigger cell damage through binding to cellular macromolecules.

Similar findings were reported by Abouzeinab (2013); Nasr (2013); Abdel-Wahhab et al. (2014) and Basuony et al. (2015) who reported that; cisplatin-Induced hepatotoxicity in male rats. The current results agreed with Juma (1984) and McDonald et al. (2003) who reported that; cyclophosphamide-induced toxicity in the human liver. Also; these results are in agreement with the previous findings of Kamboj and Sandhir (2011) and Valentovic et al. (2014) who observed a significant 
decline in serum biochemical parameters due to cisplatin treatments.

In the current study, our histopathological and immunohistochemical results showed that treatment of rats with aqueous extract of rosemary showed moderate to a good degree of improvement in the liver structure and functions as compared with Etoposide group.
In the current study a moderate atrophied vacuolar degeneration hepatocyte, some apoptotic cells with deeply eosinophilic cytoplasm and small deeply stained pyknotic or fragmented nuclei, marked cellular infiltrations and marked dilation or congestion in central and portal veins were observed in liver after treatment with Etoposide.
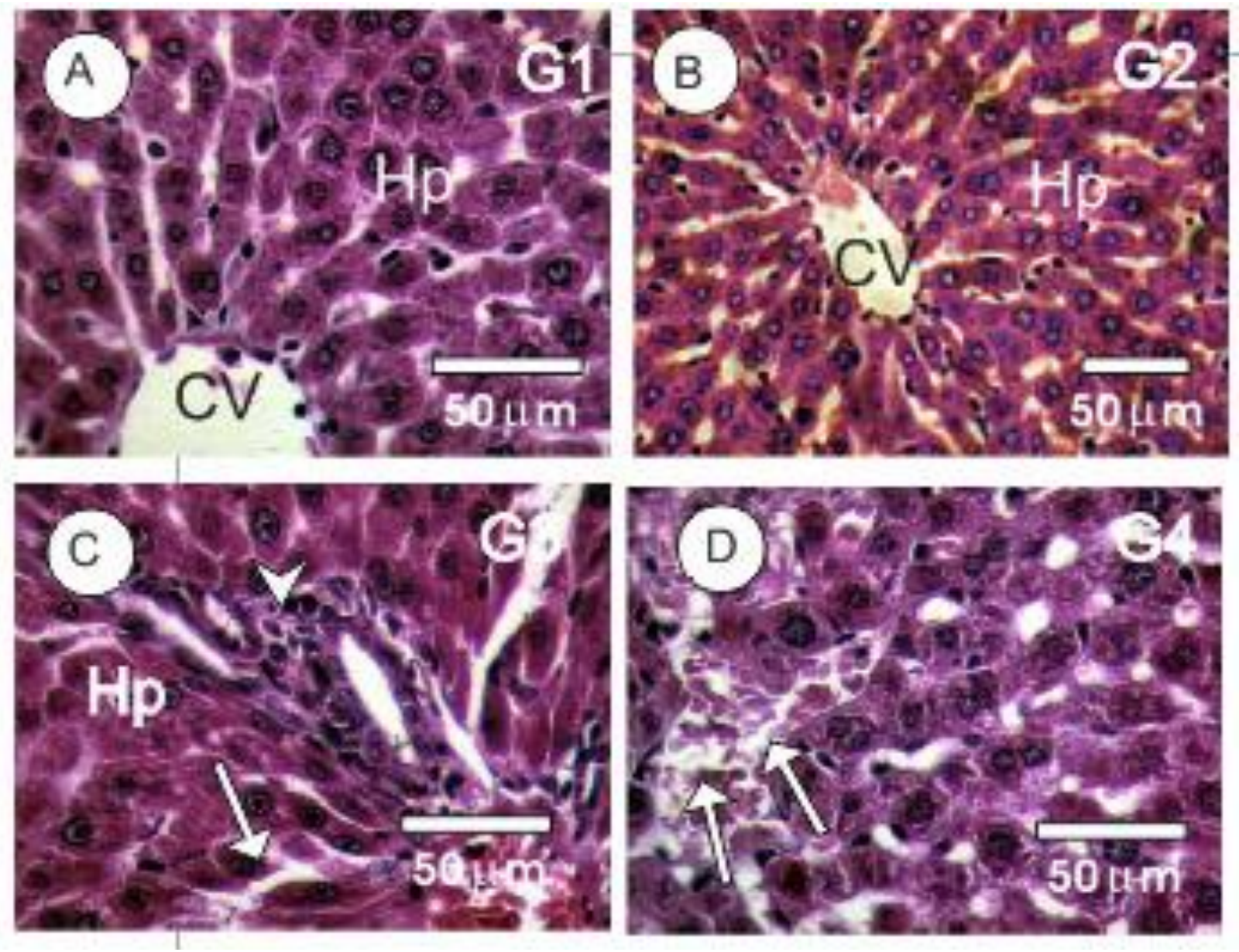

Figures 1A-1D: Photomicrographs of rat liver sections in the different experimental groups stained with Haematoxylin \& Eosin. A\&B: Liver sections in control and rosemary groups revealed normal liver structure with hepatocytes (Hp). C: Liver sections in Etoposide group revealed exhibited moderate atrophied vacuolar degeneration hepatocytes (White arrows), some apoptotic cells with deep eosinophilic cytoplasm, marked cellular infiltrations (arrow heads) and marked dilation or congestion in central and portal veins. D: Liver sections of co-treated Etoposide with rosemary revealed moderate vacuolated hepatocytes (White arrows) with mild cellular infiltrations. 

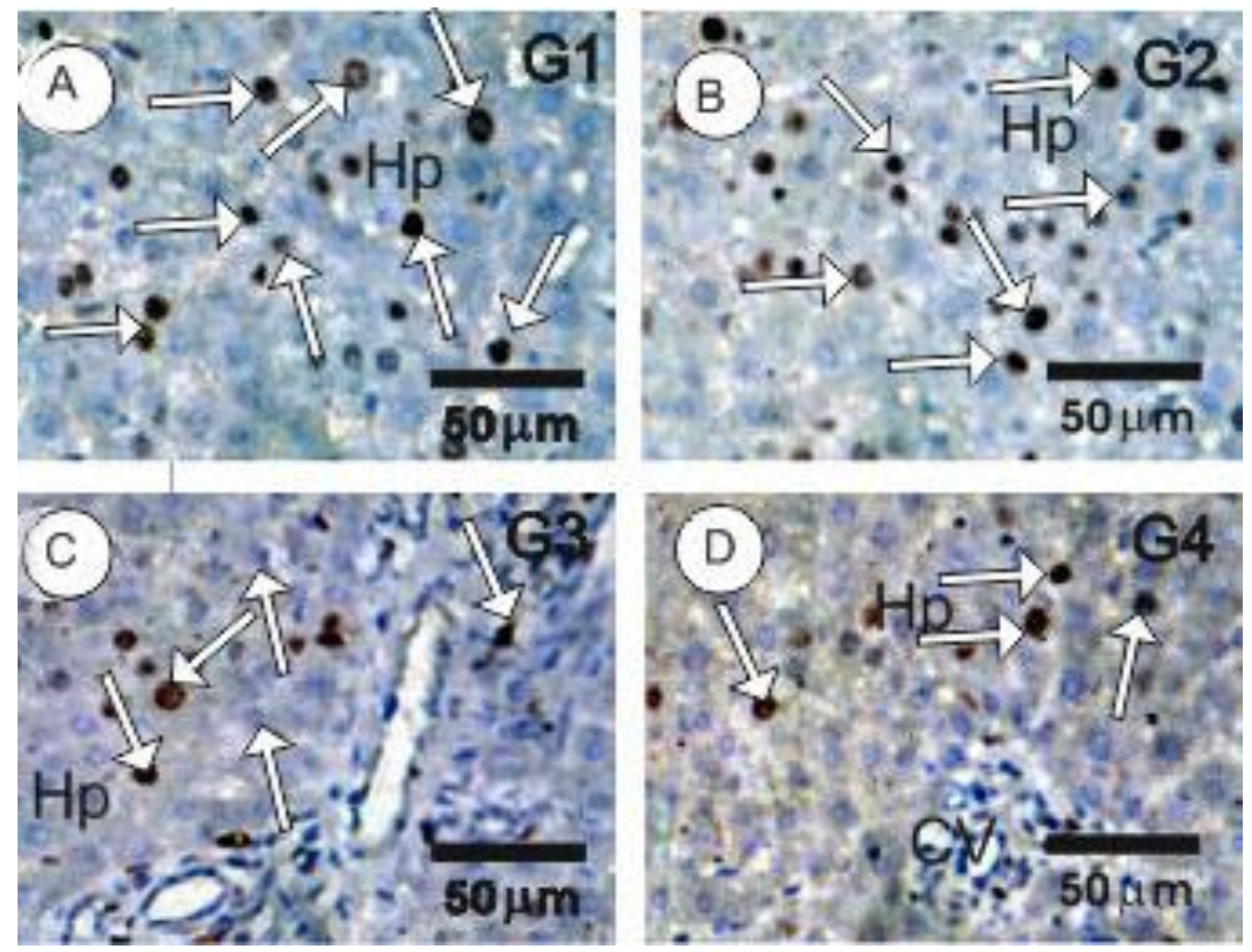

Figures 2A-2D: Photomicrographs of rat liver sections in the different experimental groups stained with Ki67-ir. A\&B: Liver sections in control and rosemary groups show moderate positive reaction for Ki67-ir (arrows) in hepatocytes. C: Liver sections in Etoposide rats group showed mild positive reactions in hepatocytes were detected for Ki67-ir. D: Moderate positive reactions for Ki67-ir were observed in hepatocytes in liver sections of co-treated Etoposide with rosemary (arrows).

Our results agreed with Tousson et al. (2014a,b) who find that ginseng extract acts as a protective and ameliorated effect on MTX-induced hepatic and renal toxicity.

Proliferating cell nuclear antigen (PCNA) or Ki-67 known as cyclin, is a non-histone nuclear protein whose level of synthesis correlates directly with rates of cellular proliferation and DNA synthesis (Tousson et al., 2011). Antibodies to the cell-cycle-associated Ki-67 protein have been widely used for more than a decade as markers of proliferative cells. In the current study; a significant decrease in KI67 expression in liver sections after treatment with Etoposide when compared with control. In contrast, co-treatment Etoposide with rosemary extract increases the depletion of Ki67 expressions in the liver.

\section{References}

Abd Eldaim, M.A., Tousson, E., El Sayed, I.E.T., Awd, W.M. (2018). Ameliorative effects of Saussurea lappa root aqueous extract against Ethephon-induced reproductive toxicity in male rats. Environmental toxicology, 2018:1-10.
Abdel-Wahhab, M.A., El-Denshary, E.S., ElNekeety, A.A., Hassan, N.S., Abu-Salem, F.M., Sarhan, N.A., Rihn, B.H. (2014). Impact of soy isoflavones on aflatoxininduced oxidative stress and hepatotoxicity in rats. General Health and Medical Sciences, 1(2): 9-14.

Abouzeinab, N.S. (2013). Cytoprotective effect and antioxidant properties of silymarin on cisplatin induced hepatotoxicity in rats: A biochemical and histochemical study. International Journal of Cancer Research, 9(1):9-23.

El-Atrash, A., Zaki, S., Tousson, E., Shoir, M.A. (2017). Protective potential of grape seed extract against monosodium glutamate induced liver toxicity and oxidative stress in young rats. Journal of Advanced Trends in Basic and Applied Science, 1(3):257-262.

Akela, M.A., El-Atrash, A., El-Kilany, M.I., Tousson, E. (2018). Qualitative and quantitative characterization of biologically active compounds of Rosemary (Rosmarinus officinalis) Leaf Extract. Journal of 
Advanced Trends in Basic and Applied Science, 2(1):59-64.

Bancroft, J.D., Stevens, A., Turner, D. (1990). Theory and practice of histological technique 3rd ed. Churchill, Livingstone, Edinburgh, London.

Basuony, M., Hafez, E., Tousson, E., Massoud, A., Elsomkhraty, S., Eldakamawy, S. (2015). Beneficial role of Panax ginseng root aqueous extract against Cisplatin induced blood toxicity in rats. American Journal of Biological Chemistry, 3(1): 1-7.

Doumas, B. T., Watson, W. A., Biggs, H. G. (1971). Albumin standards and the measurement of serum albumin with bromcresol green. Clinica Chimica Acta, 31(1): 87-96.

Tousson, E., Elgharabawy, R.M., Elmasry, T.A. (2018a). Grape Seed Proanthocyanidin Ameliorates Cardiac Toxicity Induced by Boldenone Undecylenate through Inhibition of NADPH Oxidase and Reduction in the Expression of NOX2 and NOX4. Oxidative Medicine and Cellular Longevity, 1-12.

Tousson, E., Hafez, E., Zaki, S., Gad, A. (2016). The cardioprotective effects of L-carnitine on rat cardiac injury, apoptosis, and oxidative stress caused by amethopterin. Environmental Science and Pollution Research, 23(20): 20600-20608.

Tousson, E., Bayomy, M.F., Ahmed, A.A. (2018b). Rosemary extract modulates fertility potential, DNA fragmentation, injury, KI67 and P53 alterations induced by etoposide in rat testes. Biomedicine \& Pharmacotherapy., 98: 769-774.

Elmasry, T. A., Al-Shaalan, N. H., Tousson, E., ElMorshedy, K., Al-Ghadeer, A. (2018). Star anise extracts modulation of reproductive parameters, fertility potential and DNA fragmentation induced by growth promoter Equigan in rat testes. Brazilian Journal of Pharmaceutical Sciences, 54(1):1-10.

El-Moghazy, M., Zedan, N.S., El-Atrsh, A.M., ElGogary, M., Tousson, E. (2014). The possible effect of diets containing fish oil (omega-3) on hematological, biochemical and histopathogical alterations of rabbit liver and kidney. Biomedicine \& Preventive Nutrition, 4(3): 371-377.
Hafez, E., El-Atrash, A., El-Basuoney, H.A., Tousson, E. (2017). Protective role of silymarin against anticancer drug Glivecinduced testicular damage in adult male rats. Advanced Trends in Basic and Applied Science, 1(2):128-134.

Habtemariam, S. (2016). The therapeutic potential of rosemary (Rosmarinus officinalis) diterpenes for Alzheimer's disease. Evidence-Based Complementary and Alternative Medicine, 114.

Juma, F.D. (1984). Effect of liver failure on the pharmacokinetics cyclophosphamide. European journal of clinical pharmacology, 26(5):591-593.

Kamboj, S.S., Sandhir, R. (2011). Protective effect of $\mathrm{N}$-acetylcysteine supplementation on mitochondrial oxidative stress and mitochondrial enzymes in cerebral cortex of streptozotocin-treated diabetic rats. Mitochondrion, 11(1):214-222.

McDonald, G.B., Slattery, J.T., Bouvier, M.E., Ren, S., Batchelder, A.L., Kalhorn, T.F., Schoch, H.G., Anasetti, C., Gooley, T. (2003). Cyclophosphamide metabolism, liver toxicity, and mortality following hematopoietic stem cell transplantation. Blood, 101(5):2043-2048.

Bayomy, M.F., Tousson, E., Ahmed, A.A. (2017). Protective role of rosemary against anticancer drug Etoposide-induced testicular toxicity and oxidative stress in rats. Journal of Advanced Trends in Basic and Applied Science, 1(2):1-5

Moss, D.M., Henderson, A.R. 1999. Tietz Textbook of Clinical Enzymology. WB Saunders Co: Philadelphia, PA, USA, 617-721.

Nasr, A.Y. (2013). Morphological, biochemical, histological, and ultrastructural protective effects of misoprostol on cisplatin inducedhepatotoxicity in adult male rats. Saudi Medical Journal, 34(12):1237-1247.

Al-Rasheed, N.M., El-Masry, T.A., Tousson, E., Hassan, H.M., Al-Ghadeer, A. (2018). Hepatic protective effect of grape seed proanthocyanidin extract against Gleevecinduced apoptosis, liver Injury and Ki67 alterations in rats. Brazilian Journal of Pharmaceutical Sciences, 54(2):1-6. 
Al-Rasheed, N.M., El-Masry, T.A., Tousson, E., Hassan, H. M., Al-Ghadeer, A. (2017). Protective Potential of Grape Seed Proanthocyandins Extract against Glivec (Imatinib Mesylate) Induced Liver Toxicity and Oxidative Stress in Male Rats. Annual Research \& Review in Biology, 20(6): 1-9.

Oyouni, A.A.A., Saggu, S., Tousson, E., Rehman, H. (2018). Immunosuppressant drug tacrolimus induced mitochondrial nephrotoxicity, modified PCNA and Bcl-2 expression attenuated by Ocimum basilicum L. in CD1 mice. Toxicology Reports, 5:687-694.

Saggu, S., Sakeran, M.I., Zidan, N., Tousson, E., Mohan, A., Rehman, H. (2014). Ameliorating effect of chicory (Chichorium intybus L.) fruit extract against 4-tert-octylphenol induced liver injury and oxidative stress in male rats. Food and chemical toxicology, 72:138-146.

Saleh, R.M., Awadin, W.F., Elseady, Y.Y., Waheish, F. E. (2014). Renal and cardiovascular damage induced by cisplatin in rats. Life Science Journal, 11(2):191-203.

Schumann, G., Klauke, R. (2003). New IFCC reference procedures for the determination of catalytic activity concentrations of five enzymes in serum: preliminary upper reference limits obtained in hospitalized subjects. Clinica chimica acta, 327(1-2):69-79.

Shin, H.J., Kwon, H.K., Lee, J.H., Anwar, M.A., Choi, S. (2016). Etoposide induced cytotoxicity mediated by ROS and ERK in human kidney proximal tubule cells. Scientific reports, 6:1-13.

Elmasry, T. A., Al-Shaalan, N. H., Tousson, E., ElMorshedy, K., \& Al-Ghadeer, A. (2017). P53 expression in response to equigan induced testicular injury and oxidative stress in male rat and the possible prophylactic effect of star anise extracts. Annu Res Rev Biol, 14(1):1-8.

Tousson, E., Ali, E.M., Ibrahim, W., Mansour, M.A. (2011). Proliferating cell nuclear antigen as a molecular biomarker for spermatogenesis in PTU-induced hypothyroidism of rats. Reproductive sciences, 18(7):679-686.

Tousson, E., Atteya, E., El-Atrash, A., Jeweely, O.I. (2014a). Abrogation by Ginkgo Byloba leaf extract on hepatic and renal toxicity induced by methotrexate in rats. Journal of Cancer Research and Treatment, 2(3): 44-51.

Tousson, E., Hafez, E., Zaki, S., Gad, A. (2014d). P53, Bcl-2 and CD68 expression in response to amethopterin-induced lung injury and ameliorating role of 1-carnitine. Biomedicine \& Pharmacotherapy, 68(5): 631-639.

Tousson, E., Hegazy, M., Hafez, E., Ahmed, E.A. (2014c). The effect of L-carnitine on amethopterin-induced toxicity in rat large intestine. Journal of Cancer Research and Treatment, 2(3):55-63.

Tousson, E., Ibrahim, W., Barakat, L., \& Abd ElHakeem, A. (2015). Role of Proplis administration in boldenone-induced oxidative stress, Ki-67 protein alterations and toxicity in rat liver and kidney. International Journal of Scientific \& Engineering Research, 6 (8):660-664.

Tousson, E., Zaki, Z.T., Abu-Shaeir, W.A., Hassan, H. (2014b). Methotrexate-induced hepatic and renal toxicity: role of L-carnitine in treatment. Biomed Biotechnol, 2(4):85-92.

Valentovic, M.A., Ball, J.G., Brown, J.M., Terneus, M.V., McQuade, E., Van Meter, S., Hedrick, H.M., Roy, A.A., Williams, T. (2014). Resveratrol attenuates cisplatin renal cortical cytotoxicity by modifying oxidative stress. Toxicology in Vitro, 28(2):248-257. 